\title{
ACIDENTES OFÍDICOS CAUSADOS POR Bothrops moojeni: RELATO DE 37 CASOS
}

\author{
Joao Aris KoUyolmidian (1) \& Cristina Polizelall (2)
}

\begin{abstract}
RESUMO
Foram estudados 37 casos de acidentes ofidicos causados por Bothrops moojeni na regiáo de Sảo José do Rio Preto. Sảo Paulo. durante um periodo de 5 anos ioutubro 1982 a setembro 1987). Desse total. 34 apresentaram sintomatologia clínica. sendo indicado administração de antiveneno. Sảo apresentados aspectos epidemiológicos relacionados à idade. sexo, horário do acidente. atividade do paciente no acidente. segmento corpóreo atingido e atitude inicial do paciente frente ao acidente: os resul. tados sāo semelhantes aos padrōes já conhecidos no Brasil. O quadro clínico revelou dor e edema (usado como critério para avaliaçáo da gravidade) em $100 \%$, tempo de coagulaçāo prolongado incoagulável em $72,7^{\prime} \%$ e hemorragia sistêmica em $5.8 \%$. As complicaçoes descritas em $29.4^{\prime} i$ dos casos. surgiram apenas nos grupos em que a avaliação inicial era moderado ou grave ióbito. sindrome compartimental. necrose. infeç̧ào e retraçoes musculares) e nào puderam ser evitadas mesmo com administraçáo maior e mais precoce de antiveneno. Os acidentes por Bothrops moojeni produzem maior gravidade local (edema necrose infecçà e maior percentagem de tempo de coagulaçào prolongado incoagulàvel quando comparado aos causados por Bothrops jararaca
\end{abstract}

UNITERMOS: Acidente ofídico humano: Acidente botrópico humano: Bothrops moojeni.

\section{INTRODUÇĀO}

Os acidentes ofidicos causados por serpen tes do genero Bothrops (acidentes botrópicos) sáo responsáveis por cerca de $90 \%$ dos casos de envenenamento por serpentes peçonhentas no Brasil $^{3}+5.12 .18$. Dentre as 20 espécies descritas no território nacional, destaca-se como causa dora de maior número de acidentes a Bothrops jararaca que, segundo estatisticas do Instituto Butantan, Hospital Vital Brasil, é responsável por $93.5 \%$ dos acidentes botrópicos com identifi caçāo do animal ${ }^{\overline{ }}$. A casuistica de acidentes ofidi cos na regiảo de São José do Rio Preto. Sāo Pau lo. tem revelado grande incidencia de casos em que a serpente agressora e identificada comc Bothrops moojeni como pudemos caracterizar em trabalhos anteriores ${ }^{3}$ 10. "1". A descriçāo desse tipo especifico de acidente botrópico nāo tem sido feito em nosso meio, pois nas grandes ca

Trabaho realizado no Hospital de Base da Fundacao Faculdade Regional de Medicina de Sao Jose do Rio Preto. Sao Paulo Brasil

1) Professor Assistente do Departamento de Medicima Integrada e Chefe da Disciplina de Neurologia do Hospital de Base da Fundaça Faculdade Regional de Medicina de San Jose do Rio Preto. Av. Hrig. Faria Lma. 5416 CEP 15090 Sáo Jose do Rio Preto, SP. Brasil.

2) Medica Chefe da Unidade de Terapia Intensiva do Hospital de Base da Fundaça Faruldade Regional de Medieina de Sao Jose do Rio Preto. SP. Brasil 
KOUYOUMDJIAN, J. A. \& POLIZELLI. C. - Acidentes ofidicos causados por Bothrops moojeni: relato de 37 casos Rev. Inst. Med. trop. São Paulo, 30 (6): $424-432,1988$.

suísticas do Instituto Butantan, Hospital Vital Brasil, essa serpente nem aparece como responsável por acidentes ${ }^{5}$.

O objetivo do presente trabalho é relatar os achados clínico-epidemiológicos, bem como aqueles relacionados ao tratamento e complicações de 37 casos de acidentes por Bothrops moojeni.

\section{MATERIAL E MÉTODOS}

Todos os casos de acidentes ofídicos que de ram entrada no Hospital de Base da Fundação Faculdade Regional de Medicina de Sâo José do Rio Preto, São Paulo, no período de outubro de 1982 a setembro de 1987, foram estudados de maneira prospectiva. Os casos foram cadastrados em um protocolo especialmente feito para o estudo de acidentes ofidicos na regiāo.

Foram selecionados para o presente traba lho, 37 casos em que a serpente agressora foi identificada como Bothrops moojeni. A identificação foi feita no Departamento de Zoologia, IBILCE/UNESP, Săo José do Rio Preto, Sāo Paulo.

Os itens enfatizados foram: sexo, idade, distribuição geográfica, horário do acidente, atividade do paciente no acidente, segmento corpóreo atingido, atitude inicial frente ao acidente, identificação da serpente, quadro clínico, tempo de coagulação, soroterapia, tempo de normali zação do tempo de coagulaçāo, complicações e tempo de internação.

O exame do tempo de coagulacāo (TC) foi feito colocando-se $2 \mathrm{ml}$ de sangue em banho-ma ria a $37^{\circ} \mathrm{C}$ e a cada minuto verificando-se se hou ve coagulaçāo (normal até 10 minutos, prolon gado de 11 a 30 minutos e incoagulável quando maior que 30 minutos).

Todos os antivenenos utilizados foram do Instituto Butantan: soro antibotrópico $110 \mathrm{ml}$ neutralizando $25 \mathrm{mg}$ de veneno botrópicol ou na falta desse, soro anti-ofídico $(10 \mathrm{ml}$ neutralizando $20 \mathrm{mg}$ de veneno botrópicol. A adminis tração do antiveneno foi predominantemente realizada por via endovenosa.

As complicaçōes clínicas e/ou cirúrgicas fo ram tratadas no mesmo hospital em setor com petente. Em alguns casos não foi possivel o se guimento a longo prazo para a avaliaçäo de complicaçōes tardias do quadro clínico.

Os métodos estatísticos utilizados foram: média, desvio padrão e distribuição t-Student com limite de confiança de $95 \%$ e grau de liberdade $n-1$.

\section{RESULTADOS}

\section{Sexo}

O sexo masculino correspondeu a 28 casos $(75,7 \%)$ e o feminino a 9 casos $(24,3 \%)$.

\section{Idade}

O paciente mais jovem apresentava $20 \mathrm{me}$ ses e o mais velho 83 anos.

A tabela 1 mostra a distribuiçāo dos aciden. tes de acordo com faixas etárias. A maior incidência ocorreu na 2 . década ( 13 casos $-35,1 \%$ ).

TABELA 1

Acidentes por Bothrops moojeni: relação com idade

\begin{tabular}{rcc}
\hline Década & Casos & Percentagem \\
\hline $0-10$ & 3 & $8,1 \%$ \\
$11-20$ & 13 & $35,1 \%$ \\
$21-30$ & 4 & $10,8 \%$ \\
$31-40$ & 4 & $10,8 \%$ \\
$41-50$ & 4 & $10,8 \%$ \\
$51-60$ & 5 & $13,5 \%$ \\
$>61$ & 4 & $10,8 \%$ \\
\hline
\end{tabular}

\section{Distribuição Geográfica}

A figura 1 mostra o mapa da regiāo de Sāo José do Rio Preto, onde estão assinalados os 10 cais de procedência dos acidentados. Observa-se que existem dois eixos básicos, um ao norte e outro a oeste da cidade referéncia, onde se concentra a maioria dos acidentes por Bothrops moojeni.

\section{Horário do Acidente}

Os acidentes foram divididos em três grupos de acordo com o horário em que ocorreu: manhà (06:00 - 12:59 horas), tarde (13:00 - 18:59 horas) e noite 1 19:00 - 05:59 horas). O período da manhã correspondeu a 18 casos $(48,6 \%)$, o da tarde a 12 casos $(32,4 \%)$ e o da noite a $7 \operatorname{casos}(19 \%)$. 
KOUYOUMDJAN. J A. \& POLIZELLI, C. - Acidentes ofidicos rausados por Bothrops moojeni: relatude 37 ("asis Rev. Inst. Med. trop. Sāo Paulo, $30(6)$ : 424432,1988

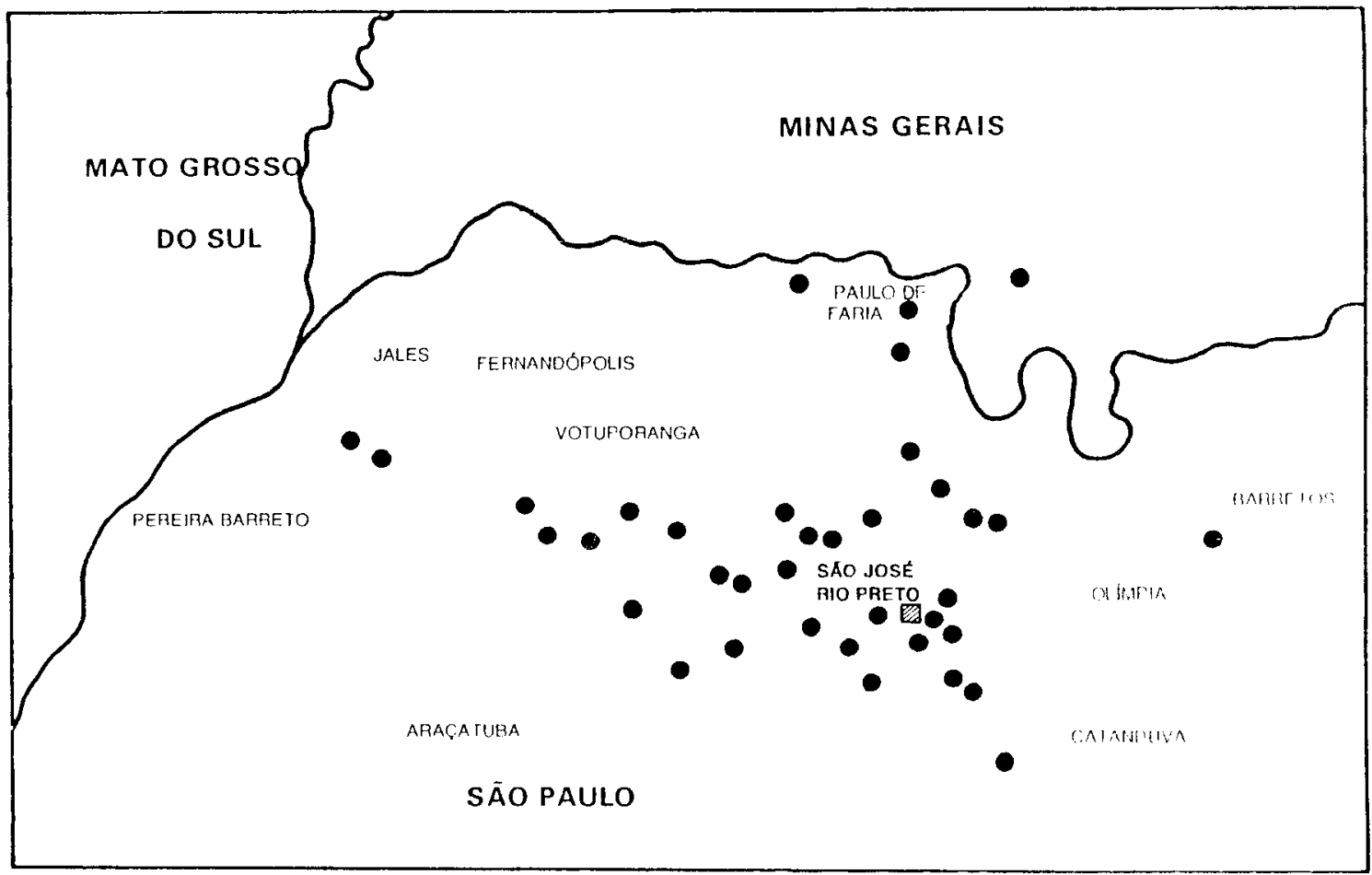

Fig. 1 - Acidentes por Bothrops moojeni: localiząáo geografica dos casos na regiáo de Sáo José do Rio Preto. Sao Paulo.

\section{Atividade do Paciente}

A atividade do paciente no momento do acidente foi dividida em três grupos: lazer (caça, pesca ou no caso de crianças, brincandos, traba lho e outros não definidos. O grupo de lazer cor respondeu a 9 casos $(24,3 \%)$, o do trabalho com 22 casos $(59,5 \%)$, sendo que em 7 casos foi especificamente relacionado à cultura de cafó, e finalmente 6 casos $(16,2 \%)$ no grupo de outros náo definidos.

\section{Segmento Corpóreo Atingido}

A tabela 2 mostra a distribuiçăo dos acidentes com relação ao segmento corpóreo atingido Observa-se que praticamente três quartos dos casos corresponderam ao terço inferior da perna. tornozelo ou pé e um quarto às mãos.

\section{Atitude Inicial do Paciente}

A atitude inicial do paciente faz referencia ao procedimento realizado por ele imediatamen te após a picada: em alguns casos esses procedi mentos foram múltiplos. Em 25 casos $(67,5 \%)$
TABELA 2

Acidentes por Bothrops moojeni: segmento corpóreo atingido

\begin{tabular}{ccc}
\hline Segmento corpóreo & Casos & Percentagem \\
\hline $\begin{array}{c}\text { Pé } \\
\text { Tornozelo } \\
\text { Inf. Perna }\end{array}$ & 27 & $73 \%$ \\
\hline Mão & 9 & $24,3 \%$ \\
\hline Outros & 1 & $2,7 \%$ \\
\hline
\end{tabular}

houve garroteamento: em 10 casos $127 \%$ foi colo cado fumo no local da picada: em 7 casos (18.9\%, nada foi feito e finalmente em 5 casos $(13.5 \%)$ outros procedimentos não médicos foram feitus.

\section{Identificação da Serpente}

No período estudado coutubro de 1982 a se tembro de 1987) foram catalogados 42 casos em que a serpente agressora foi identificada como gênero Bothrops. A distribuiçāo com relação às 
KOUYOUMDJIAN, J. A. \& POLIZELLI. C. - Acidentes ofidicos causados por Bothrops moojeni: relatode 37 casos. Rev. Inst. Med. trop. Sāo Paulo, $30(6): 424432,1988$

espécies foi a seguinte: Bothrops moojeni 137 casos $-88 \%$ ), Bothrops alternatus (4 casos $9,5 \%)$ e Bothrops jararaca ( 1 caso $-1,5 \%$ ).

\section{Quadro Clínico}

Para a análise do quadro clínico inicial foram considerados 34 casos, pois em três pacientes nāo houve qualquer tipo de sintomatologia ou anormalidade laboratorial que justificasse presença de envenenamento. O tempo de coagulaçāo será abordado dentro do quadro clínico, pois é parte integrante do diagnóstico de acidentes ofídicos. A tabela 3 sintetiza os achados clíni. cos descritos e correlaciona o TC e hemorragias sistêmicas com a graduação dos efeitos locais. Ocorreram mais casos de TC prolongado quanto menor intensidade dos efeitos locais.

\subsection{Efeitos Locais}

Os efeitos locais definidos como dor e edema, ocorreram em todos os casos $(100 \%)$, sendo imediatos (até 30 minutos do acidente) em 32 casos $(94,1 \%$ ) e não imediatos (até 2 horas do acidente) em 2 casos $(5,9 \%)$. A intensidade, e extensảo dos efeitos locais serviu para classificar os acidentes em leve ( $L$ ), moderado (M) e grave (G). Nos acidentes leves $(+)$ o edema estava apenas peri-picada; nos moderados $(++)$ estava regionalmente e nos graves $(+++$ ) estava em todo membro atingido. Dessa forma, 7 casos foram classificados como leve $(20,6 \%), 22$ casos como moderado $(64,7 \%)$ e 5 casos como grave $(14,7 \%)$. Nāo houve diferença entre os diferentes grupos de gravidade com relação a antecedentes mórbidos importantes tais como diabetes mellitus, vasculopatias definidas, insuficiência renal, hipertensāo arterial grave ou doenças hematológicas. As médias de idade foram progressivamente maiores nos grupos leve, moderado e grave, 23.4, 35,0 e 41,2 anos respectivamente. A significância estatística desses valores é prejudicada pela pequena amostra nos grupos grave e leve.

\subsection{Tempo de Coagulaçāo}

O TC esteve prolongado em 24 casos $172.7 \%)$ na admissão do paciente, sendo que não foi realizado em 1 caso.

\subsection{Hemorragia Sistêmica}

Ocorreram hemorragias sistemicas thematúria e hemorragia digestiva alta) em 2 casos $(5,8 \%)$, sem nenhuma conseqüencia grave, pois foram episódios isolados.

\section{Soroterapia}

Da mesma forma que o item anterior, foram analisados 34 casos em que a soroterapia foi indicada. A tabela 4 mostra os valores médios com indice de confiabilidade de $95 \%$ dos sub-itens estudados em todos os 34 casos; a tabela 5 corre laciona alguns sub-itens estudados com os diferentes grupos de gravidade inicial $(\mathrm{L} / \mathrm{M} / \mathrm{G})$.

\subsection{Tempo para Soroterapia Inicial}

Tempo médio decorrido entre o acidente $\mathrm{e}$ a administração do antiveneno: 3 horas e $24 \mathrm{mi}$ nutos \pm 43 minutos (todos os casos), 5 horas e 10 minutos \pm 3 horas e 20 minutos (leve), 3 horas e 4 minutos \pm 41 minutos (moderado) e

TABELA 3

Acidentes por Bothrops moojeni: relaçāo entre os subgrupos leve, moderado e grave (efeitos locais), tempo de coagulaçāo e hemorragia sistêmica.

\begin{tabular}{|c|c|c|c|c|}
\hline & \multirow{2}{*}{$\begin{array}{l}\text { Efeitos } \\
\text { locais }\end{array}$} & \multicolumn{2}{|c|}{ Tempo de Coagulaçãot* } & \multirow{2}{*}{$\begin{array}{c}\text { Hemorragia } \\
\text { sistêmica }\end{array}$} \\
\hline & & $\begin{array}{l}\text { Prolongado/ } \\
\text { incoagulável }\end{array}$ & Normal & \\
\hline Leve $(+)$ & $7(20,5 \%)$ & $7(100 \%)$ & $0(0 \%)$ & $0(0 \%)$ \\
\hline Moderado $(++)$ & $22(74,8 \%)$ & $14(66,6 \%)$ & $7(33,3 \%)$ & $2(9 \%)$ \\
\hline Grave $(+++)$ & $5(14,7 \%)$ & $3(60 \%)$ & $2(40 \%)$ & $0(0 \%)$ \\
\hline TOTAL & $34(100 \%)$ & $24(72,7 \%)$ & $9(27,3 \%)$ & $2(5,8 \%)$ \\
\hline
\end{tabular}

(*) TC não realizado em 1 caso 
KOUYOUMDJIAN, J. A. \& POLIZELLI, C. - Acidentes ofidicos causados por Bothrops moojeni: relatode 37 casos Rev. Inst. Med. trop. São Paulo, 30 (6): 424-432, 1988

3 horas e 12 minutos \pm 2 horas e 23 minutos (grave).

\subsection{Quantidade Inicial de Antiveneno}

Quantidade inicial média de antiveneno bo trópico, calculado em miligramas de veneno a serem neutralizados: $15 \mathrm{l}+18 \mathrm{mg}$ (todos os casos), $127 \pm 62 \mathrm{mg}$ (leve), $146 \pm 24 \mathrm{mg}$ (moderado) e $175 \pm 76 \mathrm{mg}$ (grave).

\subsection{Tempo para Soroterapia Adicional}

Antiveneno botrópico adicional foi indicado em 14 casos $(41,1 \%)$ na persistência de TC prolon gado ou na evidente progressão dos efeitos locais para maior gravidade. O tempo médio para soro terapia adicional foi de 16 horas e 25 minutos \pm 9 horas e 46 minutos

\subsection{Quantidade Adicional de Antiveneno}

A quantidade adicional média de antivene no botrópico calculado em miligramas de veneno a serem neutralizados foi de $88 \pm 25 \mathrm{mg}$.

\subsection{Quantidade Total de Antiveneno}

Quantidade total (inicial mais adicional) média de antiveneno botrópico administrado, cal culado em miligramas de veneno a serem neutralizados: $187 \pm 26 \mathrm{mg}$ (todos os casos), $150 \pm 74$ $\mathrm{mg}$ (leve), $173 \pm 32 \mathrm{mg}$ (moderado) e $274 \pm 79$ mg (grave).

\section{Tempo de Normalizaçāo do TC após Soro- terapia}

O tempo médio para normalizaçāo do TC após a admissāo e tratamento dos pacientes com antiveneno botrópico foi de $17 \pm 4$ horas, como é mostrado na tabela 4.

\section{Complicações}

As complicaçōes ocorreram em 10 casos $(29,4 \%)$ e foram exclusivamente locais. Näo houve casos de choque, coagulação intravascular disseminada ou insuficiência renal grave, apesar da ocorrência de um óbito de causa indetermi nada. Em alguns casos as complicaçoes se soma ram em um mesmo paciente. A tabela 6 mostra a distribuição das complicaçōes e correlaciona as com a avaliação inicial $\operatorname{dos} \operatorname{casos}(\mathrm{L} / \mathrm{M} / \mathrm{G}$ ). Todos os casos com necrose ocorreram no grupo inicial grave; não houve qualquer tipo de compli caçāo no grupo inicial leve. Relativamente ao sexo, garroteamento prévio e localização da pi cada, o grupo inicial grave mostrou percenta gens semelhantes em relaçāo aos grupos mode rado e leve. Relativamente à idade contudo, hou ve diferença nas médias dos três grupos, sendo de 41,2 anos no grupo grave, 35 anos no mode rado e 23,4 anos no leve.

\section{1. Óbito}

Houve um óbito $(2,9 \%$ ) ocorrido no 3 : dia de evoluçāo; o acidente foi considerado grave na

\section{TABELA 4}

Acidentes por Bothrops moojeni: terapia com antivenenotempo, concentraçóes neutralizantes e normalizaço do TC.

\begin{tabular}{|c|c|c|}
\hline & $\begin{array}{l}\text { Tempo } \\
\text { (minutos })\end{array}$ & $\begin{array}{l}\text { Dose }(\mathrm{mg} \text { de } \\
\text { veneno a ser } \\
\text { neutralizado) }\end{array}$ \\
\hline Antiveneno Inicial & $\begin{array}{c}204 \pm 43 \\
(3 \mathrm{hs} 24 \mathrm{~min} \pm 43 \mathrm{~min})\end{array}$ & $151 \pm 18$ \\
\hline $\begin{array}{l}\text { Antiveneno Adicional } \\
\qquad(14 / 34)\end{array}$ & $\begin{aligned} 985 & \pm 586 \\
(16 \mathrm{hs} 25 \mathrm{~min} & \pm 9 \mathrm{hs} 46 \mathrm{~min})\end{aligned}$ & $88 \pm 25$ \\
\hline Antiveneno Total & - & $187 \pm 26$ \\
\hline $\begin{array}{c}\text { Normalizaçāo do TC } \\
(21 / 34)\end{array}$ & $\begin{aligned} 1020 & \pm 240 \\
(17 \mathrm{hs} & \pm 4 \mathrm{hs})\end{aligned}$ & - \\
\hline
\end{tabular}

TABELA 5

Acidentes por Bothrops moojeni: terapia com antiveneno nos subgrupos leve, moderado e grave refeitos locais

\begin{tabular}{|c|c|c|c|c|}
\hline & Casos & Leve & Moderado & Grave \\
\hline Antiveneno Inicial ${ }^{*}$ & 34 & $127,1 \pm 62,9$ & $146.5 \pm 24.7$ & $175.0 \pm 76,1$ \\
\hline $\begin{array}{l}\text { Tempo decorrido para } \\
\text { administraçáo inicial de } \\
\text { antiveneno (min) }\end{array}$ & 34 & $\begin{aligned} 310,0 & \pm 200,7 \\
5 \mathrm{hs} 10 \mathrm{~min} & \pm 3 \mathrm{hs} 20 \mathrm{~min}\end{aligned}$ & $\begin{array}{c}184,0 \pm 41,3 \\
3 \mathrm{hs} 4 \mathrm{~min} \pm 41 \mathrm{~min}\end{array}$ & $\begin{aligned} 192,0 & \pm 143.4 \\
3 \mathrm{hs} 12 \mathrm{~min} & \pm 2 \mathrm{hs} 23 \mathrm{~min}\end{aligned}$ \\
\hline Antiveneno Adicional* & 14 & $53,3 \pm 14,3$ & $84,2 \pm 55,0$ & $123.7 \pm 32.7$ \\
\hline Antiveneno Total* & 34 & $150.0 \pm 74.4$ & $173.4 \pm 32.1$ & $274,0 \pm 79.8$ \\
\hline
\end{tabular}

(*) Quantidade de veneno a ser neutralizado (miligramas). 
KOUYOUMDJIAN. J. A. \& POLIZELLI. C. - Acidentes ofidicos causados por Bothrops moojeni: relato de 37 casos Rev. Inst. Med. trop. Sáo Paulo, 30 (6): 424432,1988

avaliação inicial: síndrome compartimental com fasciotomia no 2 dia de evoluçào.

\subsection{Síndrome Compartimental}

Definida como edema volumoso do membro atingido, com prejuizo à circulaçāo. Ocorreu em 2 casos $(5,8 \%)$ com fasciotomia precoce.

\subsection{Necrose}

Definida como perda tecidual (pele/subcutâneo/músculo) ou de todo segmento corpóreo atingido (amputaçâo). Ocorreu em 4 casos $(11,7 \%)$

\subsection{Infecção}

Definida como secreçāo purulenta difusa ou em forma de abscesso. Ocorreu em 5 casos $(14,7 \%)$.

\subsection{Retrações Musculares}

Definida como impossibilidade de realizar pleno movimento em um determinado grupo muscular devido a sua retraçâo fibrosa após a fase aguda do envenenamento. Ocorreu um caso $(2,9 \%)$ no grupo muscular soleus/gastrocnêmio.

TABELA 6

Acidentes por Bothrops moojeni: complicaçoes e correlaçáo com a gravidade inicial.

\begin{tabular}{|c|c|c|c|c|}
\hline Complicaçảo & $\begin{array}{r}\text { Avaliac } \\
\text { IL }\end{array}$ & G inicial & Casos & Pereentagem \\
\hline Óbito & \multicolumn{2}{|c|}{$1 G$} & 1 & $2.9 \%$ \\
\hline $\begin{array}{c}\text { Sindrome } \\
\text { Compartimentai }\end{array}$ & $1 \mathrm{M}$ & $1 \mathrm{G}$ & 2 & $5.8 \%$ \\
\hline Necrose & \multicolumn{2}{|c|}{$4 G$} & 4 & $11,7 \%$ \\
\hline Infecça & $3 \mathrm{M}$ & $2 G$ & 5 & $14.7 \%$ \\
\hline $\begin{array}{l}\text { Retraçōes } \\
\text { Musculares }\end{array}$ & \multicolumn{2}{|c|}{$1 \mathrm{M}$} & 1 & $2.9 \%$ \\
\hline
\end{tabular}

$\mathrm{L}=$ leve: $\mathbf{M}=$ moderado: $\mathrm{G}=$ Grave

\section{Tempo de Internação}

A tabela 7 mostra o tempo médio total de internaçāo (8.1 \pm 3.2 dias). Para o grupo de acidentes sem complicações essa média foi de 4,2 $\pm 1,0$ e para o grupo com complicaçōes foi de $17,6 \pm 9,1$.
TABELA 7

Acidentes por Bothrops moojeni: tempo de in ternaçāo.

Tempo de internaçāo (dias)

\begin{tabular}{cr}
\hline Sem complicaçóes & $4,2 \pm 1,0$ \\
Com complicaçóes & $17,6 \pm 9.1$ \\
Total & $8,1 \pm 3,2$ \\
\hline
\end{tabular}

\section{DISCUSSÃO}

Na região de Sảo José do Rio Preto, Sāo Pau Io, a grande maioria dos acidentes botrópicos é causado por Bothrops moojeni ( $88 \%$ ). Nảo pu demos encontrar outras casuisticas nas quais a serpente agressora fosse predominantemente dessa espécie, apesar de sua ocorrência em re giōes quentes e secas de Sāo Paulo, Paraná, Mi nas Gerais, Goiás e Maranhāo ${ }^{4}$. Sāo serpentes muito rábidas, perigosas podem dar botes sucessivos, projetando praticamente todo o corpo e produzem até $300 \mathrm{mg}$ de veneno na extração máximat.

Os dados epidemiológicos obtidos com relaçâo a sexo, idade, atividade do paciente, horário do acidente, segmen to corpóreo atingido e atitu de inicial do paciente após o acidente foram se. melhantes às obtidas em outras casuísticas de acidentes ofidicos no Brasil ${ }^{3.5}$ 5. 10. 12. 13. 18 , chamando-se atençāo para o fato de que $32 \%$ dos acidentes relacionados ao trabalho ocorreram na cultura de café.

O quadro clinico apresentado pelos pacientes revelou que em todos havia presença de efei tos locais (dor e edema imediatos principalmente), em quase $73 \%$ havia prolongamento do tempo de coagulaçāo, sendo que em apenas $6 \%$ houve hemorragias sistèmicas. Os nossos casos apresentaram maior percentagem de TC prolon gado em relaçāo a outras casuísticas ${ }^{14 .}{ }^{16}$, sendo parecido apenas com a de $\mathrm{HAAD}^{8}$ em Letícia, Amazonas, em que as serpentes agressoras são principalmente Bothrops atrox. A classificação da gravidade inicial do acidente foi feita baseada nos efeitos locais, sendo que em quase $80 \%$ ele foi considerado moderado ou grave. Todas as complicações observadas foram devidas a açảo local do veneno, apesar de descriçóes na 


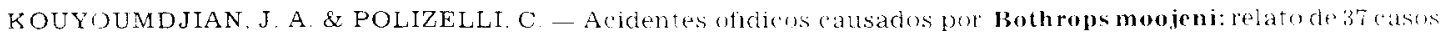

Rev. Inst. Med, trop. Sajo Paulo, $30(6): 424432,1988$

literatura de choque, insuficiència renal e coagu laçäo in travascular disseminada ${ }^{1,2,6,16.14}$. A pesar do tempo médio para administração de antive neno ter sido menor e da quantidade de antiveneno médio ter sido maior nos grupos de gravi dade inicial moderado e grave, as complicaçóes ocorreram somente nesses grupos, mostrando que aparentemente existe diferença qualitativa e não apenas quantitativa nos diferentes casos. Em 41\% dos acidentados houve necessidade de administraçào adicional de antiveneno após em media 16 horas, sendo indicado tanto na persis. téncia de TC prolongado como na franca evoluçāo dos efeitos locais. Se somarmos a quantidade de antiveneno inicial e adicional. verificaremos que nos casos de gravidade inicial leve houve neutralização média de $150 \mathrm{mg}$ de veneno, nos moderados $173 \mathrm{mg}$ e nos graves $274 \mathrm{mg}$; ainda assim as complicaçóes ocorreram somente nos dois ultimos grupos. O tempo médio para nor malizaçāo do TC após administraçào de antive neno foi de 17 horas, que achamos estar de acor do com o tempo necessário para restabelecimen. to dos niveis plasmáticos de fibrinogènio ${ }^{12}$. Como fizemos a aferiçāo do TC de $8 / 8$ ou de $12: 12$ horas, o tempo de normalização não representa o numero exato de horas para restabelecimento do fibrinogênio. Deve-se salientar que as hemor ragias sistèmicas nāo tem necessariamente relaçao direta com a desfibrinogenaçào: podem ocorrer com TC/fibrinogênio normais s" e sảo cau sadas primariamente pelos fatores hemorrági $\cos$.

O principal problema que enfrentamos na conduçào de um acidente com Bothrops moojeni foi sem dúvida a evoluçāo dos efeitos locais. Sabemos pelo trabalho de SILES VILLARROEL et $\mathrm{al}^{20}$ que entre os venenos de Bothrops moojeni, B. jararaca, B. neuwiedi, B. jararacussu, B. alternatus, B. pradoi e B. cotiara, o que induziu a maior aça necrótica em cobaias brancas foi o de B. moojeni. Ficou também plenamente demonstrado que as áreas de necrose depende ram diretamente da quantidade de veneno ino culado e do tempo decorrido para a administraçáo do antiveneno, sendo observado que apos 2 horas de ação do veneno, o antiveneno dimi nuia muito pouco ou quase nada a extensāo da necrose subsequente. Nos nossos casos humanos pudemos fazer claramente a distinção entre ede ma inicial (classificado em leve, moderado e gra ve de acordo com sua extensāol e subsequente mente, no decorrer de horas ou dias, o apareci mento de flutuação, infecçāo e ou necrose em subcutâneo geralmente com in tegridade da pele, concordando com a evolução descrita em outras revisōes ${ }^{15,17}$. O veneno, apesar de nảo ser prima riamente miotóxico, pode sem dúvida induzir a reaçōes fibróticas com retrações músculo ten dineas e incapacidade funcional. Diferentemen te da miotoxicidade sistêmica do veneno crotá lico. a miotoxicidade botrópica deve-se à ação global do veneno nos tecidos próximos ao ponto de inoculaçäo do veneno; com isso podemos ter casos com maior probabilidade de sequelas funcionais, dependendo da proximidade de músculos e tendōes. As complicaçóes nos nossos casos ocorreram em $30 \%$ e foram divididas em sindro me compartimental $(6 \%)$, necrose $(12 \%)$, infec çāo $(15 \%)$ e retraçóes musculares $(3 \%)$; houve um óbito $(3 \%)$. Esses valores estāo próximos aos obtidos no Hospital de Doenças Tropicais, Goiánia ${ }^{14}$ e elevados em relação aos do Hospital Vital Brasil, Sà Paulo ${ }^{7}$. A fasciotomia precoce deve ser indicada quando existir dificuldade ao fluxo sanguíneo, porém a contra indicação é formal na presença de $\mathrm{TC}$ prolongado ${ }^{16}$. O edema, mesmo quando maciço, pode melhorar bastante após administraçäo de antiveneno ${ }^{15}$. As compli. caços encontradas não foram precipitadas ou agravadas por doenças sistèmicas prévias nos diferentes grupos de gravidade. Contudo, a ida de não pode ser descartada como fator contri buinte de gravidade como foi observado nos nos sos grupos.

A quantificação de veneno e posteriormente dos anticorpos por ELISA ${ }^{15.19}$ está trazendo. sem dúvida alguma enorme contribuição na com. preensão da relação entre quadro clinico e quantidade de veneno, com implicaçoes diretas no tratamento especifico e das complicaçoes.

Concluindo, podemos propor un quadro cli. nico provisional para o acidente humano causado por Bothrops moojeni: 1, o prolongamento do TC ocorre em $73 \%$, semelhante aos acidentes por Bothrops atrox: 2. os efeitos locais são gra ves, levando a um número maior de complica. çóes em relaçāo aos acidentes por Bothrops jararaca: 3 as hemorragias sistêmicas sảo pouco fre. qüentes e benignas: 4 . as complicaçoes ocorreram somente nos casos inicialmente classifica- 
KOUYOUMDJIAN, J. A. \& POLIZELLI, C. - Acidentes ofidicos causados por Bothrops moojeni: relato de 37 casos.

Rev. Inst. Med. trop. São Paulo, $30(6)$ : 424-432, 1988

dos como moderados ou graves, supostamente com maior inoculaçāo de veneno: 5 . a administraçāo de antiveneno inicial em concentrações neutralizantes muito mais elevadas e em tempo mais rápido nos casos classificados inicialmente como graves não impediu o aparecimento de complicações. Como acreditamos que o tempo médio decorrido entre o acidente e a administraçāo do antiveneno dificilmente poderá baixar de 60 a 120 minutos e nesse prazo concluímos que o antiveneno não previne sensivelmente $o$ aparecimento de complicações locais, podemos inferir que em determinados casos o tratamento cirúrgico nos primeiros dias do acidente, após normalização do TC, poderia ser benéfico; estudos sistematizados sāo necessários. O principal fator prognóstico nos nossos casos foi a classificação inicial do quadro, diretamente relacionado, provavelmente, à quantidade de veneno inoculado.

\section{SUMMARY}

\section{Snake bites accidents caused by Bothrops moojeni: Report of 37 cases.}

During a period of 5 years (October 1982 September 1987), 37 cases of snake bites caused by Bothrops moojeni in Sâo José do Rio Preto, Sāo Paulo (Southeast Brazil) were studied. An tivenom therapy were indicated in 34 cases with clear evidence of envenomation. Epidemiological aspects related to age, sex. accident time, victims activities, localization of bites and first attitude of the victims after bite were showed without any great difference when compared from other sites of Brazil. The clinical picture have revealed pain and swelling (initial evaluation: mild, moderate and severe) in $100 \%$, nonclotting blood (beside test) in $72.7 \%$ and systemic bleeding in $5.8 \%$. Complications were described in $29.4 \%$ and appeared just in cases where the initial evaluation were classified into moderate or severe. They were described as death, compartment syndrome, necrosis, infection and muscular retractions, and cannot be prevented even using large amount of antivenom 3 hours after accidents. When compared with the snake bites caused by Bothrops jararaca (the most common in Brazil), Bothrops moojeni accidents have produced higher incidence of non-clotting blood and local swelling/necrosis.

\section{AGRADECIMENTOS}

Professor-Doutor Valdir Antonio Taddei, Chefe do Departamento de Zoologia, IBILCE UNESP - Sáo José do Rio Preto, Sāo Paulo, pela identificação das serpentes.

Professor Wanderley Polizelli, Chefe da Dis ciplina de Bio-estatística da Fundaçāo Faculdade Regional de Medicina de São José do Rio Preto, São Paulo, pelo estudo estatístico.

\section{REFERÊNCIAS BIBLIOGRÁFICAS}

. AMARAL, C. F. S.: SILVA, O. A.; GODOY, P. \& MIRAN DA, D. - Renal cortical necrosis following Bothrops jara. raca and $B$. jararacussu snake bite. Toxicon. 23: 877885 , 1985

2. AMARAL, C. F. S.; REZENDE, N. A.; SILVA, O. A ; RI BEIRO, M. M. F ; MAGALHẢES, R. A ; REIS, R. J : CARNEIRO, J. G. \& CASTRO. J. R. S. - Insuficiència renal aguda secundária a acidentes ofídicos botrópico e crotálico. Análise de 63 casos. Rev. Inst. Med. trop. S. Paulo, 28: $220 \cdot 227,1986$.

3. ANÁLISE epidemiológica dos acidentes ofídicos no Brasil. In: Ministério da Saúde/Secretaria Nacional de Açôes Básicas de Saúde - Secretarias de Saúde das Unidades Federadas - Anexo II do aviso circular $205 \mathrm{GM}$ de 27,0586 .

4. BELLUOMINI, H. E. - Conhecimentos sobre as serpentes brasileiras e medidas de prevençāo de acidentes. Rev. bras. Saúde ocup., 12:82-96, 1984

5. CARdoso, J. L. C. \& BRANDO, R. B. - Acidentes por animais peçonhentos: clinica e tratamento. Sảo Paulo, Livraria e Editora Santos, 1982.

6. CUPO, F.; AZEVEDO-MARQUES, M. M.; HERING, S. E \& MENEZES, J. B. - Acidentes ofidicos: análise de 102 casos. Rev. Soc. bras. Med. trop., 18 (supl.): 23-24, 1985.

7. FRANÇA. F. O. S. \& CARDOSO.J. L. C. - Estudo retros pectivo da evoluçào de acidentes botrópicos. Rev. Soc. bras. Med. trop., 20 (supl.): 56, 1987

8. HAAD, J. S. - Accidentes humanos por las serpientes de los generos Bothrops e Lachesis. Mem. Inst. Butantan. 44.45: $403.423,1980: 81$.

9. KOUYOUMDJIAN, J. A. \& KOUYOUMDJIAN, N. C. V - Acidentes ofídicos: estudo de 46 casos na regiăo de Sảo José do Rio Preto. Ars Cvrandi, 19: 55-92, 1986

10. KOUYOUMDJIAN, J. A.; ABDELNUR, C. P.; FARES. G F.; FONSECA, M. G. \& KOUYOUMDJIAN, N. C. V. Envenenamentos ofidicos na regiāo de Sảo José do Rio Preto. Estudo prospectivo de 49 casos. Rev. Soc. bras. Med. trop., 19 (supl.): 27, 1986. 
KOUYOUMDJiAN, J. A. \& POLIZELLI, C. - Acidentes ofidicos causados por Bothrops moojeni: relato cle 37 casos Rev. Inst. Med. trop. Sāo Paulo, 30 (6): 424 432, 1988

:1. KOUYOUMDJIAN, J. A.: FONSECA, M G : POLIZELLI. C.: FARES, G. F.: NAKAOSKI. S. C. B.: ANANIAS, M P. \& KOUYOUMDJIAN, N. C. V. - Acidentes ofidicos causados por Bothrops moojeni na regiao de Sāo José do Rio Preto: estudo de 27 casos. Rev. Soc. bras. Med. trop., 20 isupl.): 53, 1987.

12. MANUAL de diagnóstico e tratamento de acidentes ofidi cos. Ed. rev. Brasilia, Ministério da Saúde, 1987. (Série Normas e Manuais Técnicos, 35)

13. PEREIRA. P. C. M.: BARRAVIERA, B \& MARCONDES J. - Acidentes por serpentes venenosas - estudo clinico de 48 casos. Rev. Soc. bras. med. trop., 18 isupl.): 26.27. 1985

14. PINTO, R. N. L : SOUZA, L. C. S : SILVA, A M : PERET RA, L. I. A. \& ANDRADE, J, G. - Estudo clínico epide miológico de 774 casos de acidentes ofidicos. Rev. Soc. bras. Med. trop., 20 (supl.): 56, 1987.

15. REID, H. A. \& THEAKSTON, R. D. G. - The management of snake bite. Bull. Wld. HIth. Org., 61: 885-895. 1983.

16. RIBEIRO, L. A : JORGE, M. T. \& CARDOSO, J. L. C. - Fatores prognósticos em acidentes por serpentes do género Bothrops. Estudo de 307 casos. Rev. Soc. bras. Med. trop., 18 (supl.): 28. 1985

17. ROSENFELD, G. - Symptomatology. pathology and treatment of snake bites in South America. In: BU CHERL, W.; BUCKLEY, E. \& DEULOFEU, V Venomous animals and their venoms. New York, Academic Press. 1965. cap. 34, p. $345 \cdot 383$

18. ROSENFELD, G. - Animais peçonhentos e toxicos do Brasil In: LACAZ, C. da S ; BARUZZI. R. \& SIQUEIRA JUNIOR, W. - Introdução à geografia médica do Brasil Sāo Paulo, Edgard Blücher. EDUSP. 1972, cap. 19, p. $430-475$.

19. THEAKSTON. R. D. G. - The application of immunoas say techniques, including enzyme linked immunosorbent assay (ELISA), to snake venom research. Toxicon, 21 $341-352,1983$

20. VILLARROEL. M. S : ZELANTE, F : ROSA.R.R \& FUR LANETTO. R. S. - Padronizaçào da avaliaçāo da ativi dade necrosante de venenos botropicos e da potencia anti necrosante do antiveneno de $B$. jararaca. Mem. Inst. Bu tantan, 42-43: 345355,1978 : 79

Recebido para publicacáo em $28: 12: 87$ 